\title{
Nigella sativa - a Plant with Personality in Biochemistry and Experimental Medicine Researches
}

\author{
Mirela AHMADI ${ }^{1}{ }^{*}$, Mihaela SCURTU ${ }^{2,}$ Camelia TULCAN $^{1}$, Oana-Maria BOLDURA ${ }^{1}$, Cornelia \\ MILOVANOV ${ }^{3}$, Ioan $\mathrm{HUTU}^{3}$, Calin MIRCU ${ }^{3}$, Isidora RADULOV ${ }^{4}$, Dorel DRONCA ${ }^{5}$ \\ ${ }^{1}$ Department of Biochemsitry and Molecular Biology, Banat's University of Agriculture Science and \\ Veterinary Medicine "King Michael I of Romania" from Timisoara (USAMVB), Calea Aradului 119, \\ Timișoara - 300645, România. \\ ${ }^{2}$ CromatecPlus S.R.L. - Research Centre for Instrumental Analysis "Scient", Str. Petre Ispirescu, nr 1, Sat \\ Tâncăbești, Com. Snagov, Ilfov - 077167, România. \\ ${ }^{3}$ Department of Animal Husbandry. USAMVB Calea Aradului 119, Timișoara - 300645, România. \\ ${ }^{4}$ Department of Soil Science, USAMVB Calea Aradului 119, Timișoara - 300645, România. \\ ${ }^{5}$ Department of Animal Genetic Improvement, USAMVB Calea Aradului 119, Timişoara - 300645, \\ România. \\ *corresponding author: mirelaahmadi@yahoo.com
}

\begin{abstract}
The last few decades have witnessed an increased interest for the use of plant-based natural compounds for the prevention and treatment of various human ailments. The plant Nigella sativa showed great promise in that regard. Known also as black cumin the seeds of Nigella sativa were processed for use either as powder or oil/ water/alcoholic extracts. Traditionally, the seed powder served as food spice. For medical purposes the seeds were used as oil/water extracts and administrated orally or as injections. The most studied compound from this plant is thymoquinone (a monotherpernoid), which appears to be the key component that has medicinal properties. It has been shown that the seeds of black cumin possess health benefit in conditions such as heart, gastrointestinal and respiratory diseases, reproductive and neurological disorders as well as exhibiting analgesic and appetite stimulation effects. Black cumin seeds were also used in cancer prevention and treatment as well as diabetes. The seed extracts were shown to possess antimicrobial, antiparasitic, anti-inflammatory and antioxidant properties.
\end{abstract}

Keywords: biochemistry, experimental medicine, Nigella sativa.

\section{INTRODUCTION}

Due to the increasing interest in the natural compounds from the plant kingdom the last few years witnessed the accumulation of a large body of data on the biochemical, pharmacological and medical properties of these plant compounds. Thereby, natural chemical products are the basic of the oldest science in medicine. History of science showed us that for a long time the herbs and plants (roots, leaves, flowers and other anatomical parts) were the only natural remedies in traditional medicine (Odeh et al., 2014).

Since the ancient there are data that Nigella sativa, known as black cumin, panacea, blackcaraway, fennel-flower, nigella, nutmeg-flower or Roman-coriander, was used in experimental medicine (in vivo and in vitro), being a way of treatment and prevention (U.S. National Plant Germplasm System, 2000; Al-Rowais, 2002; Ahmad et al., 2013; Khan et al., 2016). Due to its 

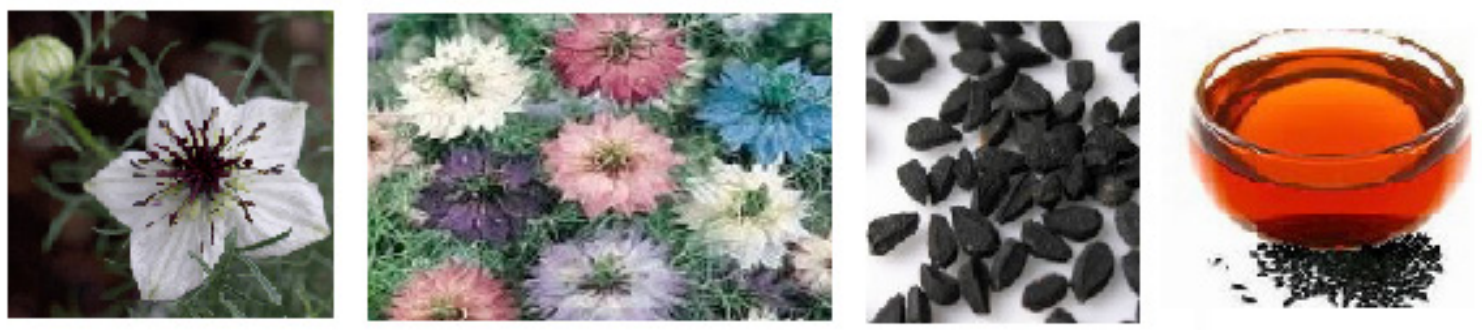

Fig. 1. Nigella sativa: flowers, seeds, oil

content in active principles, it is a valuable plant and can be used in pharmacology, medicine and food technology (Padhye et al., 2008; Mehta et al., 2009; Sharma et al., 2009; Yarnell and Abascal, 2011; Afrin et al., 2016). The anatomical parts of the plant - used as health enhancement and benefits - are seeds and fresh whole plant (Figure 1).

Nivella sativa is an annual plant, and from botanically point of view is part of Taxon: Nigella sativa L., Genus: Nigella, Family: Ranunculaceae, Subfamily: Ranunculoideae, Tribe: Nigellaea. It has white, pink, blue, or purple flowers, and is native from Asia. The plant grows up to $20-30 \mathrm{~cm}$ tall; has finely divided leaves; five to ten petals for the flower; the fruit is a large and inflated capsule that contains numerous black seeds. The seeds are used as food spice and seed oil extracts in traditional medicine.

$N$. sativa seeds contain fibres, protein (and branched chain amino acids), lipids and essential fatty acids, and also carbohydrates. The oil extract of black cumin seeds contains quinones, monoterpenoid phenols, alkaloids, saponins, phytosterols; essential lipids; and thymoquinone (Pacioretty and Babish, 2008).

Due to its content of thymoquinone and other alkaloid components - characterised by excellent therapeutical, pharmaceutical, and nutritional properties, recent progress in the study of this plant led oto the development of new products with clinical application (Crooks et al., 2001; Pacioretty and Babish, 2008).

\section{CHEMICAL COMPOSITION}

The seeds of black cumin contain various biological active principles, most of them quinoidic phenolic compounds, from which the thymoquinone is the mostimportant for biomedical reasons. Also, the seeds contain phenols; fatty acids and sterols; other terpenoids; nigellamines, vitamins such as: ascorbic acid, thiamine, tocopherols, retinol, riboflavin, folic acid, niacin, pyridoxine, ergocalciferol, phylloquinone and menaquinone; and minerals: copper, manganese, zinc, iron, cobalt, chromium, phosphor (Matthaus and Ozcan, 2011; Ahmad et al., 2013; Beheshti et al., 2016; Khan and Afzal, 2016).

$N$. sativa seeds are characterised by $4-6 \%$ moisture, $4.8 \%$ total ash, and contain $8.4 \%$ crude fibre, $26.7 \%$ protein $(3.7 \%$ branched chain amino acids), 28.5\% lipids, and 24.9\% carbohydrates (Ahmad et al., 2013; Pacioretty and Babish, 2008). The oil extract of black cumin seeds has in its composition 34-39\% quinones, monoterpenoid phenols, alkaloids, saponins, phytosterols; 0.5-1.5\% essential lipids; and up to $0.75 \%$ thymoquinone (Pacioretty and Babish, 2008).

The seeds of black cumin are rich in essential and non-essential fatty acids. The unsaturated fatty acids from $N$. sativa seeds are represented mainly by $50-60 \%$ linoleic acid, $20 \%$ oleic acid, $10 \%$ dihomolinoleic acid, and $3 \%$ eicodadienoic acid. The content of saturated fatty acids found in black cumin seeds is less of $30 \%$, mostly represented by palmitic and stearic acids. Also, the seed contain sterols, from which 44-54\% is a-sitosterol and 6.57-20.92\% stigmasterol in Iranian and Tunisian varieties of $N$. sativa seed oils (Bourgou et al., 2008; Cheikh-Rouhou et al., 2008; Mehta et al., 2008).

Protective and therapeutic properties of black cumin are partly due to the terpens represented by thymoquinone, dithymoquinone, trans-anethol, but also $p$-cymene, limonine and carvone (Khan and Afzal, 2016). Both thymoquinone and dithymoquinone have demonstrated antineoplastic and cytotoxic properties for different types of cancer, having 
equally cytotoxicity /for parenteral/ and multidrug resistance tumor cells (Crooks et al., 2001).

Nigella sativa seeds contain active alkaloid compounds, represented manly by nigellidine, nigellimine, and nigellicine (Beheshti et al., 2016). Nigellidine and nigellidine-4-0-sulfite are indazole alkaloids natural presented in black cumin seeds (Ali et al., 2008; Atta-ur-Rahman et al., 1995). Together with these alkaloids, the Nigella sativa seeds contain isoquinoline alkaloids represented by nigellicimine and nigellicimine- $\mathrm{N}$-oxide, and also indazole alkaloids such as nigellidine and nigellicine (Khan and Afzal, 2016).

\section{MEDICAL, PHARMACOLOGICAL AND NUTRITIONAL BENEFITS}

Nigella sativa ( $N$. sativa) was proved that has effective in different medical disorders, such as: hypertension; diarrhea; cardiac, digestive and respiratory diseases; liver and renal tonic; inflammations; reproductive and neural disorders, bacterial infection; dyspepsia; analgesic; appetite stimulant; cancer; bronchodilator; spasmolytic and diabetes. Also, the seeds powder, oil or extracts (hydro, alcoholic extracts) have antimicrobial, antiparasitic, antitumoral, antidiabetic, antioxidant, dermatological, anti-inflammatory therapeutic properties (Salem, 2005; Alenzi et al., 2010; Liu et al., 2013; Shabana et al., 2013; Aljabre et al., 2015; Mohtashami et al., 2015; Abamor and Allahverdiyev, 2016; Periasamy et al., 2016). Antioxidant activity is important due to thymoquinone content and it was tested on different parts of plant (shoots, roots and seeds used as extracts), results demonstrated strong antioxidant activity (Ahmad and Beg, 2016; Gholamnezhad et al., 2016).

The antioxidant and antiperoxidative effect of methanol extract and volatile oil of N.sativa seeds was evaluated on atherogenic rats. The research aim was to evaluate the conjugated diene, malondialdehyde and lipid hydroperoxide as lipid peroxidation markers in experimental rats compared to hyperlipidemic control rats, after a treatment of hyperlipidemic rats with methanol extract and volatile oil of N.sativa. The results demonstrated the efficacy of proposed and tested extracts against lipid oxidative stress and proposed different form of food supplements as prevention and treatment against free radicals activity (Ahmad and Beg, 2016).
Thymoquinone from $N$ sativa exerts antiinflammatory action; modulate humoral and cellular immune responses; provide natural cytotoxicity activity; regulates allergy symptoms, autoimmunity and cancer. Both in vivo and in vitro experiments reported the good ability of thymoquinone from black cumin seeds to modulate inflammation processes (Majdalawieh et al, 2010; Majdalawieh and Fayyad, 2015).

Female urinary tract inflammation and microbial infection can be treated by a dietary supplement formulation based on thymoquinone from $N$. sativa seed extract and cranberry fruit extract and methionine (Pacioretty and Babish, 2008).

$N$. sativa boiled extract was also tested as bronhodilatatory effect on asthmatic patients. The effect of $50 \mathrm{mg} / \mathrm{Kg}$ and $100 \mathrm{mg} / \mathrm{Kg}$ of boiled extract of $N$. sativa and $6 \mathrm{mg} / \mathrm{Kg}$ theophylline was studied of asthmatic patients. The pulmonary function tests of the patients during the experiment presented relatively potent antiasthmatic action of $N$. sativa extract, but lower effect compared to theophylline action. The main advantage of this research consists in the natural extract treatment using black cumin extract compared to any chemical drug (Boskabady et al., 2010).

Shahraki and his collaborators (2016) tested the antitumor action of a hydro-alcoholic total extract and $n$-hexane and ethyl acetate fractions of $N$. sativa, on human renal adenocarcinoma (ACHN) and normal renal epithelial (GP-293) cell lines, aiming the cell morphology, cell viability, and apoptosis. The results demonstrated that on cell survival and apoptosis, the hydro-alcoholic total extract had greater beneficial action compared to $n$-hexane and ethyl acetate fractions of N.sativa dry seeds. Also, the association of total extract, $n$-hexane and ethyl acetate fractions of N.sativa had better effect on the ACHN cell line compared to GP-293 cell line.

The nanoemulsion of black cumin essential oil (20-50 nm diameter of the droplet size) was obtain, was analytical characterized, and was tested on the viability of breast cancer cells (Michigan Cancer Foundation-7 breast cancer cells). The experiments presented very good activity of the nanoemultion on the cancer cells, by clearly induced cell apoptosis. The research could detail the apoptosis processes by membrane blebbing of the breast cancer cell, then cytoplasmic 
vacuolation, followed by marginalization of chromatin, and finally the fragmentation of the nucleus (Periasamy et al., 2016).

Antioxidant and neuroprotective effect of $N$. sativa hydro-alcoholic extract was experimentally evaluated on learning and memory improvement of neonatal and juvenile rats (Beheshti et al., 2016).

New experiments used different methods of microencapsulation of oleoresin from black cumin for nutraceutical applications. Oleoresin extraction was performed using hexane solvent, at room temperature; then the extract was microencapsulated by emulsifying the black cumin oleoresin in a solution that contained Arabic gum and maltodextrin. The resulting product indicates a very good efficiency of oleoresin and volatile oil fraction in powder with application in food technology for obtaining fortified-nutraceutical food products (Edris et al., 2016).

$N$. sativa has significant protective role on jejunal mucosal injury after treatment with gamma radiation in rats (Orhon et al., 2016).

Essential oil from $N$. sativa has been demonstrated that has vasorelaxant effect on rat aorta. The oils from black cumin seeds acted on the smooth muscle resulting relaxation and had vasorelaxing effect, by blocking both receptoroperated and voltage-sensitive calcium channels, being useful as antihypertensive agent (CherkaouiTangi et al., 2016).

Also, the N. sativa oil combination was tested in the parasitology domain with very good and promising results. $N$. sativa oil was used to obtain nanoparticles of silver doped titanium dioxide (TiAgNps) for medical treatment on Cutaneous Leishmaniasis (Leishmania tropica). The obtain formulation had non-toxic concentration of TiAgNps and black cumin oil and was used to test the antileishmanial effect on different life forms of the parasites. The experimental observations consist in evaluation of proliferation and metabolic activity, apoptosis infection index analysis and also the quantum of nitric acid production as antileishmanial efficiency. The results demonstrated high potential of effective antileishmanial effect by presented formulation, based on N. sativa oil (Abamor and Allahverdiyev, 2016).

Essential oil extract of N.sativa and other medicinal plants has demonstrated antibacterial properties tested on aquatic crustaceans, i.e on a prawn species (shrimp - sea food). The black seed oil extract showed good protection and treatment results of Artemia spp. (Fenneropenaeusindicus) afterinfection with Vibriospp.(V.parahaemolyticus). Thus, Nigella sativa oil extracts are very good treatment products, but in the same way are used in food industry to protect the sea raw food - with high impact for sea food consumers (Manju et al., 2016).

Fungal infection can be treated with alternative/traditional medicine, with natural products. Thereby, a mycological treatment methodology was propose by using hydro, alcoholic (methanolic) and chloroform extract of Mediterranean black cumin seeds for treatment of Candida albicans infection. The results proved that methanolic seeds extract had the best action, being the strongest anti-fungal activity (Bita et al., 2012; Forouzanfar et al., 2014).

Oil seeds of non-traditional food sources try to come into the food market and nutrition field to prove the nutritional prevention and therapeutically importance. Black cumin seeds oil is used for a long time in food industry due to its nutraceutical and functional properties, represented by the high content (about $85 \%$ ) of bioactive components of total content. Black cumin essential oil showed high antioxidant potential and complete inhibition zone for different Gramnegative and Gram-positive bacteria (Penicillium citrinum, Bacillus subtilis, Bacillus cereus, Pseudomonas aeruginosa, and Staphylococcus aureus) (Ramadan, 2016).

\section{TOXICOLOGICAL RESEARCH}

International literature data reported researches results on the toxicological studies in relation with ingestion on seeds, root and shoots water and/or alcoholic extracts, or oil of back cumin. In vivo experiments were also performed using injection administration of thymoquinone, and the results proved no toxicity for this biochemical compound.

The Nigella sativa fixed oil was tested for LD50 on mice and rats. The acute toxicity test was investigated for orally $(28.8 \mathrm{ml} / \mathrm{kg}$ body wt.) and intraperitoneal (2.06 ml/kg body wt.) administration, using single doses in mice. The chronic toxicity was tested in rats after a daily, oral dose ( $2 \mathrm{ml} / \mathrm{kg}$ body wt.), for 12 weeks. The 
experimental results evidenced high values for LD50, for stability of the most important hepatic enzymes (aspartate-aminotransferase - AST, alanine-aminotransferase - ALT, gammaglutamyltransferase - GGT), and also for organs (liver, kidney, heart, and pancreas) integrity (Zaoui et al., 2002).

The toxicity effect of thymoquinone was tested on male and female rats, by intraperitoneal and oral administration. The thymoquinone concentration administrated in this research was $20 \mathrm{mg} / \mathrm{kg}, 30 \mathrm{mg} / \mathrm{kg}$, and $40 \mathrm{mg} / \mathrm{kg}$ body weight - for intraperitoneal injections, and $200 \mathrm{mg} / \mathrm{kg}$, $300 \mathrm{mg} / \mathrm{kg}$ and $500 \mathrm{mg} / \mathrm{kg}$ body weight - for oral administration. The results of the experiment proved that maximum tolerant dose was $22.5 \mathrm{mg} /$ $\mathrm{kg}$ for male rats and $15 \mathrm{mg} / \mathrm{kg}$ for female rats as intraperitoneal administration and $250 \mathrm{mg} / \mathrm{kg}$ for oral administration - both for male and female rats. For $500 \mathrm{mg} / \mathrm{kg}$ body weight oral administration two rats died, as a result of complications caused by bowel obstruction (AbuKhader, 2012).

The administration of $N$. sativa seeds powder mixed in water with rat chow pellet was tested for toxicity on liver function. The tested dose was supplementation diet with $0.01 \mathrm{~g} / \mathrm{kg} /$ day powder; $0.1 \mathrm{~g} / \mathrm{kg} /$ day powder; and $1 \mathrm{~g} / \mathrm{kg} /$ day powder, for 28 consecutive days on male Sprague Dawley rats (300-350 g body weight). The experimental study demonstrated no inflammation or necrosis, and also no changes in hepatic enzymes level or toxicity effects on the liver (Dollah et al., 2013).

The black cumin seeds were characterised by very low toxicity potential, and extremely low allergenic effect. Thus, administration of seed extract and seed oil of black cumin did not induce any negative effects on hepatic or renal function (Ali and Blunden, 2003).

High dose of Nigella sativa seed oil was toxicity tested on male adult albino rats. The research consist in administration of 15 to $25 \mathrm{ml} / \mathrm{kg} \mathrm{N}$. sativa seed oil, for 1 month, during which the toxic effects were tested for liver and kidney function. Large dose of black cumin seed oil administration has toxic effects with histological modification of hepatic and renal structure (Abd Allah et al., 2012).

The literature data present very low or no toxicity of black cumin seeds or oil. Many experimental researches proved that administration of curative dosage of seeds, oil seeds, different extracts, or dietary (culinary) utilisation of Nigella sativa seeds as spice, have no toxicity effects on mice, rats, or human. Some varieties of plants can contain different chemical composition; and also the quantity of the active principles can be directly influenced by the environment conditions: like the soil and water composition, the climate and geographical region, the potential pollution in the cultivated area (Dronca, 2004). There are literature data about some programs for genetic improvement of Nigella sativa yield (quantity and quality) that demonstrated that ecotype (geographical area) are important for the content and quality of oil components from black seeds, and also the rate between the biologic active principles (Ali and Blunden, 2003; Jabeen et al., 2012; Salamati and Zeinali, 2013; Salehi et al., 2016).

\section{CONCLUSION}

Nigella sativa, commonly known also as black cumin, is a plant used from ancient times in traditional medicine and culinary filed. The seeds are used as such, but also as powder, or extracts. Most common extract are aqueous, ethanolic, aqueous-ethanolic, methanolic or glycolic extracts are used in traditional and modern medicine and pharmacy.

The most bioactive principle of Nigella sativa is the monotherpenoid compound: thymoquinone. The black cumin seeds also contain nigellamine, nigellidine, nigellimine, and nigellicine; dithymoquinone, trans-anethol, and less $p$-cymene, limonine and carvone. Other biocomponents with medical benefits are represented by lipids: unsaturated and saturated fatty acids, sterols; phenols; vitamins: ascorbic acid, ergocalciferol, folic acid, niacin, pyridoxine, retinol, riboflavin, thiamine, tocopherols; and important minerals: chromium, cobalt, copper, iron, manganese, phosphor and zinc.

Administration of $N$. sativa seeds, seed powder, seed oil, seed extracts in prescript doses does not lead to toxicity for animal or human organism. Experimental researches presented very low toxicity for black cumin seed administration or consumption.

Nigella sativa is - for all the positive presented research data - a plant with high potential in traditional medicine, being easy to cultivate, growth, preservation or storing, and offering various potential of use (seed, seed oil, different seed extracts). 


\section{REFERENCES}

1. Abamor ES, Allahverdiyev AM (2016). A nanotechnology based new approach for chemotherapy of Cutaneous Leishmaniasis: TI02@AG nanoparticles - Nigella sativa oil combinations. Experimental Parasitology, 166(7):150163.

2. Abd Allah Z, Esam Salah K, Doha Saber M, Naglaa Hamam A (2012). The possible toxic effect of different doses of Nigella sativa oil on the histological structure of the liver and renal cortex of adult male albino rat. The Egiptian Journal of Histology 35(1): 127-136.

3. AbuKhader MM (2012). The Effect of Route of Administration in Thymoquinone Toxicity in Male and female Rats. Indian J Pharm Sci 74(3): 195-200.

4. Afrin S, Kaur J, Khan MU, Khalilullah H, Osman G (2016) Nigella sativa pleiotropism: A momentary gawk. European Journal of Pharmaceutical and Medical Research 3(6):244247

5. Ahmad A, Husain A, Mujeeb M, Khan SA, Najmi AK, Siddique NA, Damanhouri ZA, Anwar F (2013). A review on therapeutic potential of Nigella sativa: A miracle herb, Asian Pac J Trop Biomed 3(5):337-352.

6. Ahmad S, Beg ZH (2016). Evaluation of therapeutic effect of omega- 6 linoleic acid and thymoquinone enriched extracts from Nigella sativa oil in the mitigation of lipidemic oxidative stress in rats. Nutrition 32(6):649655.

7. Alenzi FQ, El-Bolkiny Yel-S, Salem ML (2010). Protective effects of Nigella sativa oil and thymoquinone against toxicity induced by the anticancer drug cyclophosphamide. Br J Biomed Sci 67(1):20-8.

8. Al-Rowais NA (2002). Herbal medicine in treatment of diabetes mellitus, Saudi Med J. 23(11):1327-31.

9. Ali BH, Blunden G (2003). Pharmacological and toxicological properties of Nigella sativa. Phytother Res 17(4): 299-305.

10. Ali ., Ferreira D, Carvalho P, Avery MA, Khan IA (2008). Nigellidine-4-0-sulfite, the first sulphated indazole-type alkaloid from the seeds of Nigella sativa. J Nat Prod 71(6):1111-2

11. Aljabre SHM, Alakliby OM, Randhawa MA (2015). Dermatological effects of Nigella sativa. J Dermatology and Dermatologic Surgery 19(2): 92-98.

12. Atta-ur-Rahman, Malik S, Hasan SS, Choudhary MI, Ni C-Z Clardy J (1995). Nigellidine - A new indazole alkaloid from the seeds of Nigella sativa. Tetrahedron Letters 36(12) 1993-1996.

13. Beheshti F, Hosseini M, Vafaee F, Shafei MN, Soukhtanloo M (2016). Feeding of Nigella sativa during neonatal and juvenile growth improves learning and memory of rats. Journal of Traditional and Complementary Medicine 6(2):146-152.

14. Bita A, Rosu AF, Calina D, Rosu L, Zlatian O, Dindere C, Siminonescu A (2012). An alternative treatment for Candida infections with Nigella sativa extracts. Eur J Hosp Pharm 19.
15. Boskabady MH, Mohsenpoor N, Takaloo L (2010). Antiasthmatic effect of Nigella sativa in airways of asthmatic patients, Phytomedicine. 17(10):707-13.

16. Bourgou S, Ksouri R, Bellila A, Skandrani I, Falleh H, Marzouk B (2008). Phenolic composition and biological activities of Tunisian Nigella sativa L. shoots and roots. C R Biol 331(1):48-55.

17. Cheikh-Rouhou S, Besbes S, Lognay G, Blecker C, Deroanne C, Attia H (2008). Sterol composition of black cumin (Nigella sativa) and Aleppo pine (Pinus halpensis Mill.) seed oils. J Food Comp Anal. 21(2):162-168.

18. Cherkaoui-Tangi K, Israili ZH, Lyoussi B (2016). Vasorelaxant effect of essential oil isolated from Nigella sativa L. seeds in rat aorta: Proposed mechanism. Pak J Pharm Sci 29(1):1-8 .

19. Crooks PA, Worthen DR, Ghosheh OA (2001). Use of the Naturally-accurring quinones thymoquinone and dithymoquinone as antineoplastic and cytotoxic agents. University of Kentaky (UKnowledge). Pharmaceutical Sciences Faculty Patents. United States Patent No US 6,218,434 B1, Apr. 17, 2001

20. Dollah MA, Parhizkar S, Latiff LA, Bin Hassan MH (2013). Toxicity Effect of Nigella sativa on the Liver Function of Rats. Adv Pharm Bull 3(1): 97-102.

21. Dronca D (2004). Capitol 8: Elemente de ameliorare a plantelor, p. 187-215. In Ameliorarea animalelor şi plantelor - curs, Ed. Mirton, Timișoara.

22. Edris A, Kalemba D, Adamiec J, Piatkowski M (2016). Microencapsulation of Nigella sativa oleoresin by spray drying for food and nutraceutical applications. Food Chemistry 204(8):326-333.

23. Forouzanfar F, Bazzaz BSF, Hosseinzadeh H (2014). Black cumin (Nigella sativa) and its constituent (thymoquinone): a review on antimicrobial effects. Iran J Basic Med Sci 17(12):929-938.

24. Gholamnezhad Z, Havakhah S, Boskabady MH (2016). Preclinical and clinical effects of Nigella sativa and its constituent, thymoquinone: A review. Journal of Ethnopharmacology 190(8):372-386.

25. Jabeen R, Iftikhar T, Mengal T, Iqbal Khattak M (2012). A comparative chromosomal count and morphological karyotyping of three indigenous cultivars of Kalongi (Nigella sativa L.). Pak J Bot 44(3):1007-1012.

26. Khan AM, Afzal M (2016). Chemical composition of Nigella sativa Linn: Part 2 Recent advances. Inflammopharmacology 24(2):67-79.

27. Khan SA, Khan AM, Karim S, Kamal MA, Damanhouri GA Mirza Z (2016). Panacea seed "Nigella": A review focusing on regenerative effects for gastric ailments. Saudi Journal of Biology Sciences 23(4):542-553.

28. Liu X, Park JH, Abd El-Aty AM, Assayed ME, Shimoda M, Shim $\mathrm{JH}$ (2013). Isolation of volatiles from Nigella sativa seeds using microwave-assisted extraction: effect of volatile extracts on canine and murine CYP1A. Biomed Chromatogr 27(7): 938945.

29. Majdalawieh AF, Hmaidan R, Carr RI (2010). Nigella sativa modulates splenocyte proliferation, Th1/Th2 cytokine 
profile, macrophage function and NK anti-tumor activity. J Ethnopharmacol 131(2):268-75.

30. Majdalawieh AF, Fayyad M (2015). Immunomodulatory and anti-inflammatory action of Nigella sativa and thymoquinone: A comprehensive review. International Immunopharmacology 28(1):295-304.

31. Manju S, Malaikozhundan B, Withyachumnarnkul B, Vaseeharan B (2016). Essential oils of Nigella sativa protects Artemia from the pathogenic effect of Vibrio parahaemolyticus Dahv2. Journal of Invertabrate Pathology 136(5):43-49.

32. Matthaus B, Ozcan MM (2011). Fatty acids, tocopherol, and sterol contents of some Nigella specimen seed oil. Czech J Food Sci 29:145-150.

33. Mehta BK, Verma M, Gupta MJ (2008). Novel lipid constituents identified in seeds of Nigella sativa. Linn Braz Chem Sco 19(3):458-462.

34. Mehta BK, Pandit V, Gupta MJ (2009). New principles from seeds of Nigella sativa. Nat Prod Res 23(2):138-48.

35. Mohtashami R, Huseini HF, Heydari M, Amini M, Sadeghi Z, Ghaznavi H, Mehrzadi S (2015). Efficacy and safety of honey based formulation of Nigella sativa seed oil in functional dyspepsia: A double blind randomized controlled clinical trial. J Ethnopharmacol 175:147-52.

36. Odeh F, Al-Jaber H, Khater D (2014). Chapter 10: Nanoflora - How Nanotechnology Enhanced the Used of Active Phytochemicals (p.343-368), in Application of Nanotechnology in Drug Delivery (Sezer A. editor). InTech Publisher, ISBN 978-953-51-1628-8.

37. Orhon ZN, Uzal C, Kanter M, Erboga M, Demiroglu M (2016). Protective effect of Nigella sativa on gamma radiation-induced jejunal mucosal damage in rats. Pathology - Research and Practice 212(5):437-443.

38. Pacioretti LM, Babish JG (2008). Formulations containing thymoquinone for urinary health, United States Patent No US 20100028468 A1, Priority date Jul 29, 2008, Publication date Feb 4, 2010.

39. Padhye S, Banerjee S, Ahmad A, Mohammad R, Sarkar FH (2008). From here to eternity - the secret of Pharaohs: Therapeutic potential of black cumin seeds and beyond. Cancer Ther 6:495-510.
40. Periasamy VS, Athinarayanan J, Alshatwi AA (2016). Anticancer activity of an ultrasonic nenoemulsion formulation of Nigella sativa L. essential oil on human breast cancer cells. Untrasonics Sonochemistry 31: 449455.

41. Ramadan M (2016). Chapter 30 - Black Cumin (Nigella sativa) Oils (p 269-275), in Essential Oils in Food Preservation, Flavor and Safety - Preedy V. - editor, Academic Press (Elsevier imprint), ISBN: 978-0-12-416641-7.

42. Salamati MA, Zeinali H (2013). Evaluation of genetic diversity of some (Nigella sativa L.) genotypes using agromorphological characteristics. Iran J Med Arom Plants 29(1):201-214.

43. Salehi S, Rokhzadi A, Noormohammadi G, Mahammadjavad Mirhadi S, Golparvar AR (2016). Genetic improvement of quantitative/quality yield of black cumin (Nigella sativa L.) ecotypes cultivated in Iran climatic conditions. J Herbal Drug 6(4):187-194.

44. Salem ML (2005). Immunomodulatory and therapeutic properties of Nigella sativa L. seed. 5(13-14): 1749-70.

45. Shabana A, El-Menyar A, Asim M, Al-Azzeh H, Al Thani H (2013). Cardiovascular benefits of black cumin (Nigella sativa). Cardiovasc Toxicol 13(1):9-21.

46. Shahraki S, Khajavirad A, Shafei MN, Mahmoudi M, Tabasi NS (2016). Effect of total hydroalcoholic extract of Nigella sativa and its n-hexane and ethyl acetate fractions on ACHN and GP-293 cell lines. Journal of Traditional and Complementary Medicine 6:89-96.

47. Sharma NK, Ahirwar D, Jhade Gupta S (2009). Medicinal and Pharmacological Potential of Nigella sativa: A Review. Ethnobotanical Review 13:946-55.

48. Yarnell E, Abascal K (2011). Nigella sativa: holy herb of the middle East. Altern Compl Therap 17(2):99-105.

49. Zaoui A, Cherrah Y, Mahassini N, Alaoui K, Amarouch H, Hassar M (2002). Acute and chronic toxicity of Nigella sativa fixed oil. Phytomedicine 9(1):69-74.

50. U.S. National Plant Germplasm System (GoogleMap), Taxon: Nigella sativa L., Genus: Nigella, Family: Ranunculaceae, Subfamily: Ranunculoideae, Tribe: Nigellaea, 2000. 